Pedagogía feminista para la transformación.

El caso de la diplomatura en género en la Universidad Nacional de Quilmes

Julieta Evangelina Cano

Con X (N. $\left.{ }^{\circ} 4\right)$, e025, 2018

ISSN 2469-0333 | https://doi.org/10.24215/24690333e025

http://perio.unlp.edu.ar/ojs/index.php/conequis

FPyCS | Universidad Nacional de La Plata

La Plata | Buenos Aires | Argentina

\title{
Pedagogía feminista para la transformación
}

Feminist Pedagogy for Transformation

\author{
Julieta Evangelina Cano \\ julieta_cano1983@yahoo.com.ar \\ http://orcid.org/0000-0003-2570-5982 \\ Instituto de Cultura Jurídica \\ Facultad de Ciencias Jurídicas y Sociales \\ Universidad Nacional de La Plata \\ Argentina
}

\section{Resumen}

En este artículo se describe y se analiza, desde una perspectiva de género feminista, la propuesta pedagógica del Diploma de Operador/a Social en Prevención de Violencias de Género y Promoción de la Equidad, una diplomatura de pregrado que se desarrolló entre septiembre de 2014 y agosto de 2015. Desde un abordaje de estudio de caso, la autora da cuenta de la experiencia de la comisión 2 que se dictó en la Universidad Nacional de Quilmes (UNQUI).

Palabras clave | perspectiva de género feminista, políticas sociales, pedagogía feminista

\section{Abstract}

This article describes and analyzes, from a feminist gender perspective, the pedagogical proposal of the Social Operator Diploma in Prevention of Gender Violence and Promotion of Equity [Diploma de Operador/a Social en Prevención de Violencias de Género y Promoción de la Equidad], an undergraduate diploma that was developed between September 2014 and August 2015. From a case study approach, the authoress analyzes the experience of commission 2 that was dictated in the Universidad Nacional de Quilmes (UNQUI).

Keywords | feminist gender perspective, social policies, feminist pedagogy 


\title{
Pedagogía feminista para la transformación
}

\author{
El caso de la diplomatura en género
} en la Universidad Nacional de Quilmes

\author{
Por Julieta Evangelina Cano
}

\section{Introducción}

Este trabajo ${ }^{1}$ tiene la intención de describir y de analizar, desde una perspectiva de género feminista, la propuesta pedagógica del Diploma de Operador/a Social en Prevención de Violencias de Género y Promoción de la Equidad, organizado en forma conjunta por el Ministerio de Desarrollo Social de la Nación (MDS), ${ }^{2}$ la Facultad de Periodismo y Comunicación Social de la Universidad Nacional de La Plata (FPyCS-UNLP) y el Consejo Nacional de las Mujeres (CNM). ${ }^{3}$

Dicha diplomatura de pregrado se desarrolló entre septiembre de 2014 y agosto de 2015. Constó de cuatro módulos teóricos y de un módulo de prácticas, y se dictó en la Ciudad Autónoma de Buenos Aires y en el conurbano bonaerense; ${ }^{4}$ muchas veces, usando como sedes las universidades nacionales. Para ello, y desde un abordaje de estudio de caso, se analizará la experiencia de la comisión 2 de la Universidad Nacional de Quilmes (UNQUI), de la cual la autora fue docente en los módulos I, III, IV y en el módulo de Práctica.

El trabajo tiene un doble objetivo político: por un lado, visibilizar y, por otro, registrar esta experiencia. En este sentido, se considera importante rescatar la experiencia por dos motivos principales. En primer lugar, por el tiempo que se invirtió en el proceso de formación de los y las participantes y en su preparación para 
la intervención, que se extendió durante casi un año. Se destaca este aspecto puesto que si bien se trata de un contexto en el que «hablar de la perspectiva de género está de moda» (Lamas, 2007), las propuestas, muchas veces, no pasan de un encuentro de un par de horas en el cual se abordan cuestiones referidas a las violencias contra las mujeres de manera muy superficial. Por su duración, esta experiencia fue distinta, ya que les permitió a las y los cursantes repensar algunas cuestiones de sus propias vidas en torno a la categoría «género». Además, la articulación con sedes universitarias y la emisión de un diploma universitario (de extensión) les permitió a transitar y apropiarse del espacio de la universidad pública.

En segundo lugar, porque durante todo el dictado del curso la propuesta fue jerarquizar la posición de referentes barriales de los y las cursantes para que, por su intermedio, lleguen a los barrios propuestas de intervención. Es decir, se partió de la valorización de lo que cada persona había construido en su propio barrio, desde una perspectiva de la educación popular, y se buscó capitalizar las herramientas territoriales con las que ya contaban para realizar una transformación personal y barrial en relación con las desigualdades de género percibidas y vividas cotidianamente.

\section{Estrategia metodológica}

En este trabajo se reponen lo que se consideran casos «exitosos»; es decir, se propone como objetivo demostrar que las políticas sociales diseñadas y ejecutadas con perspectiva de género feminista impactan de manera positiva en la vida de las personas destinatarias, y es por ese motivo que en su desarrollo se recuperan los testimonios que dan cuenta de ello.

Que el conocimiento no se pueda generalizar formalmente no significa que no pueda tomar parte en el proceso colectivo de la acumulación del conocimiento en un campo determinado o en una sociedad dada. Un estudio de caso fenomenológico puramente descriptivo sin ningún intento de generalizar puede, sin duda, tener algún valor en este proceso y con frecuencia ha contribuido a abrir un camino hacia la innovación científica (Flyvbjerg, 2004, p. 45). 
Para dar cuenta de la impronta feminista en el diseño y en la ejecución de esta política, en el trabajo se analizan los materiales didácticos del curso y las notas de prensa del MDS. En tanto, para recuperar los testimonios de las personas que formaron parte de esta propuesta formativa se consideran los documentos elaborados por las y los participantes, en los cuales se indagaba acerca del impacto de la diplomatura en su cotidianeidad: líneas de tiempo y respuestas a un cuestionario de evaluación que se realizaron al final de la cursada con el objetivo de conocer sus expectativas y si se sentían diferentes una vez terminada la diplomatura. Para individualizar los relatos a lo largo del texto, se utiliza la letra $\mathrm{P}$ (que significa participante) seguida de las iniciales de la persona.

\section{Perspectiva de género feminista}

Los dispositivos educativos son tecnologías de género (De Lauretis, 1996) que tanto pueden producir y reproducir mandatos patriarcales de organización sociogenérica, como subvertirlos. En este trabajo, se aludirá a la «perspectiva de género feminista» porque, en línea con lo señalado por Alda Facio (2009), se entiende que si bien toda construcción está atravesada por una perspectiva de género esta suele ser la perspectiva del género dominante.

Los hombres también deberían hacer análisis de género desde su perspectiva, explicitando que la tienen y que esta es la perspectiva de uno de los dos sexos del género humano, en vez de hablar en nombre de la humanidad toda y como si su perspectiva fuese una NO perspectiva. En otras palabras, los hombres deberían hacer análisis de género explicitando siempre su posición privilegiada en esta sociedad con respecto a la mujer, en vez de hablar «desde ninguna parte» y en nombre del género humano. En síntesis, tanto hombres como mujeres deberían optar por incluir la categoría género como central a cualquier análisis porque esta categoría permite una visión más apegada a la realidad y por lo tanto más objetiva y científica (p. 189). 
En cualquier análisis, introducir la perspectiva de género feminista implica introducir la dimensión del poder: cómo se distribuye el poder entre los cuerpos sexuados y cómo las diferencias se traducen en desigualdades, siempre en perjuicio de las mujeres y de los cuerpos feminizados. La perspectiva de género feminista es transversal, es una propuesta de inclusión que se traduce en una búsqueda de equidad entre las personas.

Si tenemos en cuenta que los formatos educativos son performativos en cuanto a los géneros, es relevante analizar qué herramientas se desplegaron en el dictado de la diplomatura para alcanzar el objetivo que esta política se proponía lograr:

[la promoción de la] organización comunitaria y la participación social para cambiar las realidades injustas, se ha establecido como la prioridad del diseño y la implementación de políticas públicas que acompañen comunitariamente el sostenimiento de la estrategia de autovalimiento de las mujeres, reconociendo el derecho a contar con asistencia protectora en las diferentes instancias del abordaje ante casos de violencia de género (Ministerio de Desarrollo Social, 2014, p. 6).

\section{Contexto}

Las políticas sociales, entendidas como «aquellas específicas intervenciones sociales del Estado que se orientan directamente a $-\mathrm{y}$ en este sentido, producen $\mathrm{y}$ moldean- las condiciones de vida y de reproducción de la vida de distintos sectores y grupos sociales» (Danani, citada por Dallorso, 2008, p. 5), fueron una herramienta clave del gobierno kirchnerista luego de 2008, como estrategia para acentuar el carácter popular de su gestión (Basualdo, 2011) luego de la denominada «crisis con el campo», originada por la resolución 125 de aumento de las retenciones móviles.

La preeminencia de las políticas sociales se explica como estrategia de construcción de consenso y de generación de nuevas alianzas con los sectores populares ante el antagonismo surgido a partir del conflicto con el sector agrario. Estas políticas sociales y las políticas legislativas de género fueron, a su vez, una herramienta clave para el empoderamiento de los sectores populares. 
La Ley 25.673 de «Creación del Programa de Salud Sexual y Procreación Responsable» (2002), la Ley 25.929 de «Parto humanizado» (2004), la Ley 26.150 de «Creación del Programa Nacional de Educación Sexual Integral» (2006), la Ley 26.130 de «Anticoncepción quirúrgica» (2006), la Ley 26.485 de «Protección integral para prevenir, sancionar y erradicar las violencias contra las mujeres en los ámbitos en que desarrollen sus relaciones interpersonales» (2009), la Ley 26.618 de «Matrimonio igualitario» (2010), la Ley 26.743 de «Identidad de género» (2012), la Ley 26.862 de "Acceso integral a los procedimientos y técnicas médicoasistenciales de reproducción médicamente asistida» (2013), la sanción del nuevo código civil y comercial (que remite como pauta interpretativa a los tratados de Derechos Humanos en sus artículos 1 a 3), la tipificación del femicidio (por medio de la Ley 26.791 de 2012), la supresión en el Código Penal de la figura del avenimiento (Ley 26.738 de 2012), y la reforma de las leyes 26.842 de «Prevención y sanción de la trata de personas y asistencia a sus víctimas» (2012) y 26.879 de «Creación del Registro Nacional de Datos Genéticos» vinculados con delitos sexuales (2013), dan cuenta de la recepción por parte del Estado de demandas históricas de los colectivos de mujeres y feministas. ${ }^{5}$

En este contexto, las políticas sociales que tienen como destinatarias a las mujeres cobran una relevancia central, dado que empiezan a reconocer las particularidades que asume la adscripción genérica en sus cuerpos y en sus realidades. En cuanto a la diplomatura que aquí se analiza, sus destinatarios y destinatarias fueron las y los referentes barriales - principalmente, mujeres- pertenecientes a los programas Argentina Trabaja y Ellas Hacen. ${ }^{6}$ Una de las propuestas más interesantes de estos programas fue su componente formativo: ${ }^{7}$ a los y las cooperativistas se les ofrecía la posibilidad de terminar la escuela primaria y secundaria, de formarse en oficios varios y de participar de distintos diplomas de extensión universitaria.

En el marco de estos programas, y en cumplimiento del objetivo reseñado, se creó una diplomatura de extensión universitaria denominada Operador/a Social en Prevención de Violencias de Género y Promoción de la Equidad. De acuerdo a lo enunciado, esta diplomatura puede considerarse como el emergente de aquello que Pablo Scharagrodsky (2017) piensa como un clima de época en nuestro país en determinado momento histórico ${ }^{8}$ en relación con la desnaturalización del sistema patriarcal como regulador del orden social. 
La relevancia específica que tiene la creación de este diploma es que la propuesta formativa integra una política social que establece la inclusión de la perspectiva de género feminista en la formación y en la capacitación de las mujeres (y también de los varones). Esta perspectiva es la que permite visibilizar aquellas situaciones que, aunque se presenten neutrales en relación con los géneros, en los hechos impactan de maneras diferentes en los varones y en las mujeres por el solo hecho de su adscripción genérica. La iniciativa, además, se presenta en consonancia con la Ley 26.485, no solo porque incorpora la perspectiva de género sino porque concibe al colectivo de mujeres víctimas de violencias como particularmente vulnerable.

\section{La diplomatura}

La diplomatura nació con la intención de aprovechar el conocimiento sobre el territorio de las y los referentes, y de dotarlas y dotarlos de herramientas para el correcto abordaje y acompañamiento en sus barrios de las víctimas de violencias basadas en el género. Como se informó desde el MDS, de los más de 1.000 inscriptos e inscriptas con los/las que se contó al comienzo, culminaron el proceso alrededor de 800 (MDS, 29/10/2014 y 17/9/2018, en línea). Las y los participantes cursaban dos veces por semana, cuatro horas cada vez, y la asistencia a los encuentros contaba como cumplimiento de sus tareas en de la cooperativa.

La diplomatura se instrumentó en cinco módulos ${ }^{9}$ que contaron con material escrito (también denominados módulos) específicamente confeccionado para su dictado.

\section{Módulo 1}

El primer módulo, «Géneros y proyecto de país», ${ }^{10}$ introdujo las categorías clave de género y de patriarcado para pensar, luego, en las políticas públicas y en un proyecto de Estado que construya y que garantice la igualdad, todo ello en clave histórica y mediante la recuperación de la participación de las mujeres en la vida nacional de nuestro país. Entre los contenidos que figuran en el material, se destacan las referencias a la heterosexualidad obligatoria, la explicación del concepto de androcentrismo y el abordaje de la división sexual del trabajo para pensar el patriarcado como un sistema de dominación. 
En ese marco, cuando se abordó la participación de las mujeres en el espacio público se trabajó sobre las biografías de Alicia Moreau, de Carolina Muzzili y de Julieta Lanteri, en tanto precursoras de la demanda sufragista en el país, y de Eva Duarte, como la persona que coadyuvó a consolidar los derechos políticos de las mujeres al receptar la demanda de los colectivos y promover la sanción de la Ley 13.010 de sufragio universal femenino (1947). En dicho módulo también se destacó la organización de las mujeres en el marco de la última Dictadura cívico militar (Madres y Abuelas de Plaza de Mayo) y su participación en las ollas populares generadas por la crisis de 2001. También se hizo referencia a los Encuentros Nacionales de Mujeres y al movimiento LGTBIQ a través de la visibilización de dos de sus organizaciones emblemáticas: el Frente de Liberación Homosexual y la Comunidad Homosexual Argentina.

Para abordar la cuestión de género(s) y trabajo, se hizo hincapié en la división sexual del trabajo y en la doble jornada laboral, en las categorías que explican la exclusión de las mujeres de ciertos espacios de poder (techo de cristal, de cemento, de diamante, suelo pegajoso, segregación vertical y horizontal del trabajo), así como en la brecha salarial y en el lugar explicativo que en ella tiene la maternidad.

El módulo también incluye una unidad dedicada a repensar el rol del Estado como constructor de derechos humanos, lo que se planteó mediante la contraposición de dos modelos: el Estado neoliberal, caracterizado por políticas sociales mitigadoras y focalizadas, que piensa a las personas como beneficiarias, versus el Estado nacional y popular (corriente que se reivindica en el material y que se identifica con el proyecto de país inaugurado por los gobiernos kirchneristas), que implementa políticas reparadoras y constructoras de ciudadanía, y que piensa a las personas como titulares de derechos. En esta última unidad también se hizo mención a las políticas concretas desarrolladas desde 2003 en el marco de los derechos reconocidos por la CEDAW ${ }^{11}$ y por la Convención de Belém do Pará. ${ }^{12}$

Por último, se abordaron cuestiones relativas al rol de los medios de comunicación (que se profundizaron en el módulo IV) y de la educación como dispositivos de formación sexista, junto con propuestas acerca de cómo subvertirlos, entre las que se destacó la sanción de la Ley 26.522 de Servicios de Comunicación Audiovisual (2009) (en la actualidad, parcialmente suspendida) y de la Ley 26.150 que creó el Programa Nacional de Educación Sexual Integral (2009). 
El segundo módulo, «Planificación y gestión de procesos y proyectos con equidad de género», ${ }^{13}$ se avocó a brindar herramientas para la planificación de proyectos, con especial hincapié en la realización de un mapeo territorial que permitiera conocer con qué instituciones estatales y con qué organizaciones de la sociedad civil se contaba en los barrios para el abordaje de las violencias basadas en el género.

Para la formulación de proyectos, se desarrollaron las etapas de diagnóstico, de formulación, de ejecución y de evaluación, y se brindaron las herramientas para que las y los estudiantes, a través de la dinámica de trabajo en grupo, realizaran un mapeo territorial en sus barrios (no solo elementos de la comunicación sino también pautas sobre cómo se dibuja un mapa y qué significan algunos de sus símbolos).

Por último, el material brinda información acerca de las características de un proyecto comunicacional y ofrece una guía de talleres para la planificación y para la gestión de procesos y de proyectos con equidad de género.

Módulo 3

En el tercer módulo, «Estrategias de intervención en relación a la violencia de género", ${ }^{14}$ se abordaron los distintos tipos de violencias basadas en el género, su marco legal, y las expectativas y las incumbencias de un/a operador/a social con orientación en igualdad de género y en prevención de las violencias.

Entre los contenidos desarrollados, se destacan la definición de violencias de género, así como sus tipos y sus modalidades de acuerdo a lo establecido por la Ley 26.485. En el material se puntualiza cómo influyen en el abordaje de las violencias los estereotipos de género y la construcción de los mitos del amor romántico, y se ejemplifica mediante casos concretos trabajados en los medios de comunicación. ${ }^{15}$ Se problematizan los mitos y los prejuicios sobre la violencia, las víctimas y los agresores, y se brindan herramientas para intentar comprender por qué una situación de violencia puede extenderse en el tiempo: el círculo de la violencia y los factores explicativos psicológicos y sociales.

Asimismo, se desarrollaron el marco legal y las políticas públicas instauradas para intentar dar respuesta a esta problemática, y se trabajó sobre recursos concretos, como la línea telefónica 144, entre otros. Por último se problematizó la 
naturalización, la invisibilización y la impunidad de las distintas violencias basadas en el género. Sobre este punto es importante señalar que, a lo largo del material se plantea la diferencia entre femicidio y feminicidio, como también las implicancias del fallo de la Corte Suprema de Justicia de la Nación «F., A.L. s/ medida autosatisfactiva». ${ }^{16}$

En relación con la preparación del perfil de operador/a social y a la descripción de las expectativas sobre ese rol en los barrios y en la comunidad, se brindaron herramientas teóricas y prácticas para el correcto abordaje de las violencias basadas en el género; entre ellas, pautas para realizar entrevistas no revictimizantes, para leer una evaluación de riesgo y para proceder en caso de urgencias y de emergencias. Por último, y mediante el concepto de «ruta crítica» ${ }^{17}$ se detalló cómo es el procedimiento judicial para lograr el acceso a la justicia de las mujeres víctimas.

El módulo finalizó con propuestas de actividades prácticas orientadas a trabajar los conceptos desarrollados, con especial hincapié en el rol del acompañante que crea la Ley 26.485 en su artículo 10 inciso 4. En esta clave, el objetivo se orientaba a que los y las diplomadas sean capaces de reconocer y de intervenir ante situaciones de inequidad de género, y generar iniciativas que promuevan su igualdad, dado que se pretende que trabajen en sus propios barrios (por ello se eligió a referentes barriales para que participen de esta propuesta) y que actúen actuar en dos esferas de manera simultánea: la de la promoción y la prevención; y la del acompañamiento y la intervención.

\section{Módulo 4}

En el cuarto y último módulo teórico, «Comunicación popular y producción de mensajes propios», ${ }^{18}$ se desarrollaron contenidos relativos a la comunicación popular y a la producción de mensajes. Se profundizaron los conocimientos acerca de la Ley 26.522, se historizó su sanción y se puso de relieve la necesidad de la circulación democrática de la palabra, desde la perspectiva de la comunicación popular en América Latina con ejemplos de experiencias comunicacionales de organizaciones feministas. Además, se brindó información sobre sitios web institucionales que ofrecen información y materiales para trabajar las violencias basadas en el género. 
Todos los módulos finalizaron con propuestas de actividades tendientes a acercar a las y los estudiantes los diferentes temas tratados: dramatizaciones, volantes, líneas del tiempo, mapeos barriales, poemas colectivos y debate grupal. Asimismo, en todos ellos se utilizaron categorías feministas (géneros, patriarcado, heterosexualidad obligatoria, ruta crítica, etc.) y citas de teóricas feministas (Marta Lamas, Carol Pateman, Catherine MacKinnon y Kate Millet, entre otras).

\section{Módulo 5}

El quinto y último módulo, denominado «Módulo de prácticas», se propuso la aplicación en el territorio de lo aprendido y aprehendido durante los cuatro módulos previos. Divididos/as en grupos, los y las estudiantes llevaron a cabo distintas propuestas para visibilizar y para problematizar las relaciones de género impuestas por el patriarcado: desarrollo de talleres en las cooperativas, colocación de stands de difusión en lugares estratégicos, volanteadas, realización de piezas audiovisuales, producción de murales en lugares estratégicos, etcétera.

Todo el dictado de la diplomatura estuvo a cargo de parejas pedagógicas ${ }^{19}$ y tuvo la impronta de la educación popular: se ofrecía un espacio en donde los contenidos eran una excusa para el encuentro, y en donde se priorizaba la circulación de la palabra y el protagonismo de las experiencias. Cada quince días, el equipo de coordinación convocaba a una reunión con el plantel docente para establecer consensos mínimos y para resolver inquietudes teóricas y prácticas surgidas en el dictado de las clases, así como cuestiones planteadas por las y los referentes barriales. Además, proporcionaban un cronograma, organizado día por día, en el que se indicaba qué temas se podían trabajar y se sugerían actividades.

\section{La comisión 2 de la UNQUI}

Tomé la decisión de ayudarme a mí misma (P: N. R.) Si, cambié mucho, porque hoy me siento empoderada y segura (P: N. B.)

El objetivo de la diplomatura fue formar a referentes barriales con perspectiva de género feminista para brindar herramientas que les permitan intervenir correctamente en situaciones en las que se encontraban interviniendo o que se les 
pudieran presentar en relación con las violencias basadas en el género. En línea con el artículo 10 de la Ley 26.485, que plantea como una obligación del Estado llevar adelante "programas de acompañantes comunitarios para el sostenimiento de la estrategia de autovalimiento de la mujer» (inc. 4), se pretendió introducir la perspectiva de género feminista en la intervención de las personas que efectivamente realizan ese trabajo, además de certificar la formación con un diploma de pregrado.

La comisión 2 se dictó en la UNQUI. Al principio, estuvo integrada por 33 participantes estables (30 mujeres y tres varones), de los cuales 26 terminaron efectivamente la formación. Desde que comenzó la cursada y por su duración, las personas que participaron fueron variando, pero existió un «núcleo duro» que realizó la totalidad del trayecto formativo. Para garantizar la participación de los y las cooperativistas, se pagaba una beca (que consistía en una pequeña suma de dinero) que permitía afrontar el costo de los viáticos. Por cuestiones administrativas y burocráticas, esta beca tardó bastante en pagarse, cerca de tres meses después de iniciado el proyecto. Sin embargo, y a pesar de tener que solventar de su propio bolsillo los viáticos y los gastos que insumía la cursada, las y los cursantes sostuvieron durante ese tiempo la propuesta.

A fin de contribuir a reforzar con evidencia empírica la demanda de políticas sociales que incorporen la perspectiva de género feminista a las propuestas educativas, dado que estas efectivamente transforman la vida de sus destinatarios/as, a continuación se da a conocer - desde la perspectiva del actor/alo dicho por las y los participantes en el marco de un ejercicio sobre la línea de tiempo individual realizada hacia el final de la diplomatura. De este modo, la dinámica de la evaluación de las experiencias se integra con el análisis de las líneas de tiempo personales que se construyeron a partir de solicitarles que marcaran en la línea de tiempo aquellos sucesos vinculados con la diplomatura que a nivel personal habían resultado más significativos y de la pregunta que en el cuestionario de evaluación final les planteaba: «iSiento que he cambiado a partir de cursar la Diplo? ¿Por qué?».

Del análisis de esa línea de tiempo, que entregaron 20 de los participantes, surgen las reflexiones que se detallan a continuación. 
Diecisiete participantes destacaron la importancia del conocimiento obtenido a lo largo de la diplomatura, sobre todo porque la totalidad de quienes hicieron la línea del tiempo coincidieron en indicar que cuando empezaron a cursar desconocían de qué se trataba la propuesta. De hecho, al preguntarles si sus expectativas habían sido cumplidas, fue usual la contestación de que en un principio no tenían expectativas porque no sabían de qué se trataba. Esto se debe a que las y los participantes fueron seleccionados dentro de las cooperativas por coordinadores y coordinadoras territoriales del MDS.

Principalmente, fueron las mujeres quienes resaltaron lo importante que es conocer acerca de los derechos, sobre todo por las implicancias que este conocimiento tiene en un marco de naturalización de las violencias basadas en el género.

Realizamos una actividad de fortalezas y debilidades personales y me encontré con una balanza en donde me tocó mucho el haber adquirido toda esta información. La «diplo» pasó y transformó mi vida (P: N. R.).

A partir de la «diplo» empecé a cuestionar varias cosas: cómo era la sociedad en la que vivía, por qué la gente actuaba tan diferente y discriminaba a las que no eran según el patriarcado marcaba. También empecé a cuestionar mi propia familia y mi relación con mi pareja. No había notado lo mal que se veía todo hasta que lo fui aprendiendo acá. Aprendí a detectar los tipos de violencia que vivía que, al no ser física, no notaba que fuera así de grave mi situación (P: R. A.).

A su vez, el hecho de que el curso se haya dictado en la UNQUI no pasó desapercibido para las y los participantes. La universidad, aunque de acceso público y gratuito, no es una posibilidad para todos y todas, ha funcionado como un espacio de exclusión, como un lugar en donde los sectores populares no podían representarse y transitar. La mayoría de las y los participantes comentaban, con orgullo, que estaban yendo a la universidad. Y al menos cinco de las cursantes, al finalizar el diploma, expresaron su seria intención de anotarse en la universidad para formarse en enfermería y en trabajo social. 
En la línea del tiempo, más de la mitad de las mujeres (trece en total) manifestaron que les costaba mucho hablar en público, y que el trayecto recorrido en la diplomatura las había ayudado a hacer uso de la palabra.

[...] me animé a hablar en público y a debatir con mis compañeros de clase, eso me daba mucha vergüenza (P: N. B.).

\begin{abstract}
A partir del transcurso de la «diplo» mi vida dio un giro importante, ya que descubrí que podía expresarme más, cosa que me era imposible antes. La «diplo» me enseñó a ver la vida de otra forma, me siento más fuerte y segura (P: M. S.).
\end{abstract}

Este es uno de los aspectos más significativos: la introducción de la perspectiva de género feminista transforma la subjetividad de las mujeres en el día a día. Las dinámicas de educación popular, la revalorización de las experiencias que las participantes tienen para compartir y el entrenamiento de hablar al grupo en cada encuentro ayuda a que las mujeres se apropien del uso de la palabra, expongan sus ideas y sus opiniones, y cuenten sus historias. El clima de respeto por las ideas de los y las demás contribuyó, ampliamente, a que las mujeres ganaran seguridad al momento de hacer uso de la palabra en público.

Además de estos intercambios, durante el módulo de prácticas, los y las participantes tuvieron que realizar diversas tareas: en principio, exponer frente a sus compañeras y compañeros el proyecto que pensaban ejecutar y, posteriormente, realizar entrevistas a referentes, dictar talleres de sensibilización, participar de una radio abierta e interpelar a diferentes expositores y expositoras sobre diversas temáticas. Como ejemplo del resultado que arrojaron estas actividades, una de las estudiantes que comenzó el curso sin poder decir nada frente a las y los demás, terminó la cursada dictando talleres sobre derechos sexuales y reproductivos ante personas desconocidas. 
Una de las dimensiones más relevantes se relaciona con el modo en el que se contribuyó a transformar las propias prácticas imbuidas de «sentido común patriarcal». $\mathrm{Al}$ respecto, las y los participantes contaron:

Cuando empezamos a tratar el tema del patriarcado fue impactante ver cómo uno, sin darse cuenta, está atravesado por determinadas posturas de pensamiento con las que no está de acuerdo, pero termina siendo parte de esta cultura creada (P: J. M.).

Hablamos sobre el hombre, la mujer y cómo nos atraviesa el patriarcado. Fue muy impactante. Eran muchas cosas que no sabía y empecé a cuestionar mi propio actuar (P: R. A.).

Puedo ver más claro lo que he vivido (P: E. A.).

A pesar de que me creía que era muy feminista, me di cuenta que había muchas cosas que eran del patriarcado, como creer que las mujeres maltratadas se quedan porque quieren (P: M. M.).

Puedo ver el patriarcado donde antes no lo veía, les hablo a mis hijas y a mis familiares [...]. Me he potenciado con mis compañeras de grupo (P: S. R.).

Me ayudó a fortalecerme y a darme cuenta que sufrí violencia cuando estuve en pareja. Hoy me siento mucho más fuerte y con un poco menos de vergüenza para hablar o dar una opinión (P: V. S.). 
Los formatos educativos tradicionales muchas veces reproducen los postulados del orden opresivo heteronormativo y sexista (Southwell, 2011; Trujillo, 2015); pero como tecnología de género que son (De Lauretis, 1996) pueden también cuestionar, denunciar y transformar el orden patriarcal para construir órdenes más justos (Trujillo, 2015).

Si entendemos a la pedagogía feminista como una «pedagogía que parte de los cuerpos para pronunciar palabras, recuperando el valor de la subjetividad en la creación histórica, y criticando, una y otra vez, las certezas del punto de partida» (Korol, 2007, p. 18), se puede pensar que la diplomatura sobre la cual se reflexiona en este artículo tuvo casos exitosos; es decir, casos en los que se produjo - al menos, discursivamente- una transformación actitudinal que cuestiona el sentido común patriarcal. El éxito se explica no solo porque la propuesta se diseñó desde la perspectiva de género feminista, sino porque su ejecución fue abordada desde una pedagogía cuya finalidad fue la subversión del orden patriarcal que pretende organizar nuestra existencia.

El dictado del diploma interpeló a sus destinatarias para repensar sus historias, su presente y sus prácticas. Esta interpretación, como un «proceso de invitación a reconocerse en un discurso y ser parte de él» (Southwell, 2011, p. 32) fue transformadora en sentido feminista, porque fue emancipadora, y porque invitó a desarrollar una praxis feminista; es decir, a «poner nuestra acción al servicio de no reproducir ni que se reproduzcan estas situaciones de subordinación en el ámbito en el que nos toca desenvolvernos» (Maffia, 2007, p. 59). Del informe final sobre los y las estudiantes realizado por la pareja pedagógica se destaca que 19 de los/as 26 participantes dan cuenta de un manejo de los conceptos teóricos y de una reflexión sobre sus propias prácticas que permitiría intervenciones adecuadas con las mujeres víctimas de violencias en el barrio.

A lo largo de la cursada, algunas mujeres se separaron de sus parejas, algunas volvieron a escuchar la música que solían escuchar en otros tiempos de sus vidas, algunas participaron de la marcha convocada por el colectivo \#NiUnaMenos 20 convencidas. Algunas mujeres vencieron la resistencia patriarcal al reconocer la propia opresión. Las mujeres construyeron un espacio en el cual -dicho por ellas mismas- empezaron a disfrutar de la compañía de otras mujeres y a experimentar la sororidad. Además, empezaron a creer en su propia capacidad de transformación, en su capacidad de oratoria y en su propio valor como seres humanos. 
En este punto, es pertinente realizar dos reflexiones sobre lo desarrollado hasta aquí. Por un lado, la política social instrumentada tenía como objetivo brindar herramientas para el adecuado abordaje y acompañamiento de las violencias basadas en el género en el territorio $\mathrm{y}$, al menos en el caso de la comisión 2 de la UNQUI, ese objetivo fue cumplido. Por otro, si bien el dictado de la diplomatura no tenía como objetivo (explícito, al menos) la transformación personal de sus destinatarios/as, los contenidos y las actividades que se desarrollaron fueron apropiados y resignificados por gran parte de las y los participantes para transformar sus propias prácticas, lo cual es destacable y auspicioso.

$\mathrm{Al}$ principio de este trabajo se advirtió sobre la importancia de resaltar los casos exitosos y por ese motivo se recuperaron los testimonios que dan cuenta de esta transformación. No obstante, ese efecto no se produjo en todos/as los/as participantes. Tal es el caso de una de las mujeres que participó mientras atravesaba una situación de violencia con su pareja que nunca denunció. Sabemos que durante la cursada no resolvió la situación de violencia; sin embargo, finalizó la propuesta, realizó las prácticas territoriales y estudió para la evaluación integradora final. Seguramente, la cursada constituyó una disputa al interior de su pareja, pero logró culminarla. Este no es un «caso exitoso», desde la perspectiva trabajada aquí, que los presenta como aquellos en los que las/los involucradas/os logran transformar o, al menos, reflexionar sobre su propia vida. Sin embargo, ¿no es también un éxito que una mujer en situación de violencia haya logrado terminar la diplomatura disputándole ese espacio a su pareja violenta?

\section{Reflexiones finales}

Escribir este trabajo es una oportunidad para comenzar a sistematizar una experiencia educativa que, con una impronta feminista, fue dirigida, principalmente, a las mujeres de los barrios para facilitar que el Estado llegue a donde muchas veces no llega: a las personas de los sectores populares víctimas de violencias basadas en el género. La finalidad última de la propuesta fue formar operadoras y operadores territoriales que intervinieran en estos casos con las herramientas adecuadas pero, también, formar formadores/as que pudieran replicar en sus barrios lo aprendido. 
Desde el inicio, la propuesta era de transformación, y a pesar de las resistencias, que siempre las hay, muchas de las mujeres que terminaron el recorrido comenzaron a transformar sus vidas. Pequeñas prácticas de resistencia a las violencias cotidianas, al silenciamiento, a la violencia institucional y a una socialización patriarcal que nos enseña a desconfiar de la otra.

Alguna vez escuché decir que transitar por cualquiera de los feminismos era como colocarse unos lentes violetas con los que se veía la realidad diferente, y oí también que este tránsito era un camino de ida: cuando nos declaramos feministas nada vuelve a ser igual. No me consta que las y los participantes de la diplomatura se reconozcan hoy como feministas, ni tampoco sé cuáles de los cambios que realizaron en sus vidas durante el cursado persisten hasta la actualidad, cuánto se profundizaron o si se diluyeron. De lo que sí puedo dar cuenta, porque ellas y ellos así lo manifestaron en esa ocasión, es de que la pedagogía feminista es transformadora, liberadora y cuestionadora por definición, creadora de feministas populares, intuitivas y plurales, y que propone transformar las propias prácticas, la propia organización familiar, el propio barrio y la propia historia. Pero todo ello requiere de un Estado que no se incomode con la transformación y con el empoderamiento feminista y popular.

La diplomatura constituyó, entonces, una política social educativa que fue capaz de involucrar y de interpelar a las mujeres como nuevas actoras sociales, con el objetivo de paliar la desigualdad (Arriagada, 2006), y si pensamos que lo común en las propuestas formativas tradicionales es la naturalización de las relaciones de género patriarcales y la legitimación de un Estado paternalista, ambas cuestiones fueron, al menos, denunciadas y problematizadas desde este espacio.

Para finalizar, debo decir que esta experiencia transformó profundamente mi vida. Relacionada tradicionalmente con la enseñanza universitaria de grado y de posgrado, esta experiencia me conmovió en mi interior, aprendí mucho de las mujeres participantes, sobre todo la fortaleza con la que encararon un proceso que desnudaba varias formas de opresión que muchas de ellas no tuvieron dudas en cuestionar. Yo tampoco soy la misma después de «la Diplo», por lo que mi caso es, también, un caso de éxito. 


\section{Referencias}

Arriagada, I. (2006). Cambios de las políticas sociales: políticas de género y familia. Recuperado de https://repositorio.cepal.org/handle/11362/6122

Basualdo, E. (2011). Sistema político y modelo de acumulación. Tres ensayos sobre la Argentina actual. Ciudad Autónoma de Buenos Aires, Argentina: Cara o Ceca.

Dallorso, N. (2008). Entre el cuidado y el control: el rol de las «manzaneras» y «comadres» en conflictos domésticos y barriales. Presentada en el IX Congreso Argentino de Antropología Social. Posadas, Argentina: Universidad Nacional de Misiones.

De Lauretis, T. (1996). La tecnología del género. Mora, (2), 6-34.

Delmas, F. y Urtazún, C. (diciembre 2012). Recorridos, vacíos institucionales y estrategias frente a la violencia contra las mujeres. Ponencia presentada en las VII Jornadas de Sociología de la Universidad Nacional de La Plata. La Plata, Argentina.

Facio, A. (2009). Metodología para el análisis de género del fenómeno legal. En R. Ávila Santamaría, J. Salgado y L. Valladares (Comps.), El género en el derecho. Ensayos críticos (pp. 181-224). Quito, Ecuador: Ministerio de Justicia y Derechos Humanos.

Flyvbjerg, B. (2004). Cinco malentendidos acerca de la investigación mediante los estudios de caso. Reis. Revista Española de Investigaciones Sociológicas, (106), 33-62. Recuperado de http://www.reis.cis.es/REIS/PDF/REIS_106_041167998142322.pdf

González, M. y Cano, J. (2015). Violencias contra las mujeres.

Debates parlamentarios ¿en el camino a la equidad de género?

Question, 1(47), 142-161. 
Korol, C. (2007) (Comp.). Hacia una pedagogía feminista. Ciudad Autónoma de Buenos Aires, Argentina: El Colectivo, América Libre.

Lamas, M. (2007). Género: claridad y complejidad. En A. Giglia y otros (Comps.), ¿Adónde va la antropología? Ciudad de México, México: Universidad Autónoma de México.

Ley Nacional 13.010 (1947). Voto femenino. Recuperado de http://servicios.infoleg.gob.ar/infolegInternet/anexos/4500049999/47353/norma.htm

Ley Nacional 25.673 (2002). Creación del Programa Nacional de Salud Sexual y Procreación Responsable. Recuperado de http://servicios.infoleg.gob.ar/infolegInternet/anexos/7500079999/79831/norma.htm

Ley Nacional 25.929 (2004). Parto humanizado. Recuperado de http://servicios.infoleg.gob.ar/infolegInternet/anexos/9500099999/98805/norma.htm

Ley Nacional 26.150 (2006). Creación del Programa Nacional de Educación Sexual Integral. Recuperado de http://servicios.infoleg.gob.ar/infolegInternet/anexos/120000124999/121222/norma.htm

Ley Nacional 26.130 (2006). Anticoncepción quirúrgica. Recuperado de http://servicios.infoleg.gob.ar/infolegInternet/anexos/115000119999/119260/norma.htm

Ley Nacional 26.485 (2009). Protección Integral para prevenir, sancionar y erradicar las violencias contra las mujeres en los ámbitos en que desarrollen sus relaciones interpersonales. Recuperado de http://servicios.infoleg.gob.ar/infolegInternet/anexos/115000119999/119260/norma.htm 
Ley Nacional 26.522 (2009). Servicios de Comunicación Audiovisual. Recuperado de http://servicios.infoleg.gob.ar/infolegInternet/anexos/155000159999/158649/norma.htm

Ley Nacional 26.618 (2010). Matrimonio igualitario. Recuperado de http://servicios.infoleg.gob.ar/infolegInternet/anexos/165000169999/169608/norma.htm

Ley Nacional 26.738 (2012). Delitos contra la Integridad Sexual. Recuperado de http://servicios.infoleg.gob.ar/infolegInternet/anexos/195000199999/195896/norma.htm

Ley Nacional 26.743 (2012). Identidad de género. Recuperado de http://servicios.infoleg.gob.ar/infolegInternet/anexos/195000199999/197860/norma.htm

Ley Nacional 26.791 (2012). Modificaciones al Código Penal. Recuperado de http://servicios.infoleg.gob.ar/infolegInternet/anexos/205000209999/206018/norma.htm

Ley Nacional 26.842 (2012). Prevención y sanción de la trata de personas y asistencia a sus víctimas. Recuperado de http://servicios.infoleg.gob.ar/infolegInternet/anexos/205000209999/206554/norma.htm

Ley Nacional 26.879 (2013). Creación del Registro Nacional de Datos Genéticos. Recuperado de http://servicios.infoleg.gob.ar/infolegInternet/anexos/215000219999/217689/norma.htm 
Ley Nacional 26.862 (2013). Acceso integral a los procedimientos y técnicas médico-asistenciales de reproducción médicamente asistida. Recuperado de http://servicios.infoleg.gob.ar/infolegInternet/anexos/215000219999/216700/norma.htm

Maffia, D (2007). Desafíos actuales del feminismo. En C. Korol (Comp.), Hacia una pedagogía feminista (pp. 41-68). Ciudad Autónoma de Buenos Aires, Argentina: El Colectivo, América Libre

Ministerio de Desarrollo Social (17 de septiembre de 2015). Más de 800 cooperativistas terminaron la Diplomatura en Género. Recuperado de http://www.desarrollosocial.gob.ar/noticias/mas-800cooperativistas-terminaron-la-diplomatura-genero

Ministerio de Desarrollo Social (29 de octubre de 2014). «Nosotros vamos por más igualdad, más equidad, más desarrollo». Recuperado de http://www.desarrollosocial.gob.ar/noticias/nosotros-vamos-pormas-igualdad-mas-equidad-mas-desarrollo/

Scharagrodsky, P. (2017). «Sobre exclusiones, fracasos y resistencias. El primer Bachillerato trans "Mocha Celis" CABA, Argentina". En R. Cervini (Comp.), El fracaso escolar: diferentes perspectivas disciplinarias (pp. 180-196). Bernal, Argentina: Editorial UNQ.

Southwell, M. (2011). Lo social como interpelación a la pedagogía: mujeres educadoras en disputa con sus épocas. En Pedagogía Social y educación popular. Perspectivas y estrategias sobre la inclusión y el derecho a la educación (pp. 23-36). Cuadernos de trabajo 2. La Plata, Argentina: UNIPE.

Trujillo, G. (2015). Pensar desde otro lugar, pensar lo impensable: hacia una pedagogía queer. Educação e Pesquisa, (41), 1527-1540. Recuperado de http://www.redalyc.org/articulo.oa?id=29843497028 


\section{Notas}

1 Una versión preliminar de este trabajo fue presentada en las V Jornadas CInIG de estudios de Género y Feminismos, y III Congreso Internacional de Identidades, realizados en julio de 2018 .

2 A través de la Dirección Nacional de Formación de Cooperativas Protegidas de los programas «Ingreso social con trabajo» y «Ellas hacen».

3 En la actualidad, Instituto Nacional de las Mujeres.

4 El diploma se dictó en tres regiones. La zona norte incluyó los distritos Ciudad Autónoma de Buenos Aires (CABA), San Martín, San Miguel-Malvinas Argentinas, José C. Paz, Del Viso y Ezeiza. La zona oeste, La Matanza, Morón-Ituzaingó, Morón-Moreno, Luján y Tres de Febrero. Finalmente, la zona sur, La Plata, Almirante Brown, Lanús, Echeverría, Berazategui, Quilmes, Lomas de Zamora y Adrogué.

5 Es importante mencionar, de todos modos, que muchas veces las reformas legislativas iban detrás de hechos sangrientos que se cobraban vidas de mujeres (González \& Cano, 2015).

6 Ambas fueron líneas de acción específicas del MDS. El programa «Inclusión social con trabajo» fue creado por la Resolución 3182/09 y ratificado mediante el Decreto 1067/09. El programa «Ellas hacen», encuadrado dentro del primero, fue inaugurado en 2013 (Res. 2176) y tenía como destinatarias a 100 mil mujeres en condiciones de vulnerabilidad. Estos programas articulaban fuertemente con organizaciones sociales para su organización y su ejecución, fortaleciéndolas y legitimándolas en el territorio.

7 Dentro de los objetivos específicos de los programas de transferencia condicionada de ingresos, se encontraba aquel que se planteaba: «Formación en acción con perspectiva de género en: Derechos y responsabilidades de niñez, familia, género y ciudadanía urbana; Oficios vinculados con construcción y saneamiento integral urbano; Cooperativismo y asociatividad en economía social; Producción social de infraestructura urbana» (MDS, 2014, p. 40).

8 Dice el autor: «Con una intensidad semántica diferente, el orden sexuado y generizado en la Argentina comenzó a erosionarse y a ser más cuestionado. Producto de nuevos actores, imaginarios, órdenes simbólicos, movimientos sociales y políticos como los diferentes feminismos y las producciones queer y de un cuasi "receptivo" clima de época, en las últimas décadas se inició un lento proceso de crítica y de lucha contra el orden patriarcal y heteronormativo» (Scharagrodsky, 2017, p. 82). 
9 Para cada uno de los módulos el MDS y la FPyCS-UNLP editaron y repartieron, en forma gratuita, cuadernos de trabajo (tipo manual, a todo color) para estudiantes y para docentes. El material, que tenía un formato accesible y atractivo, ofrecía al final sugerencias de actividades que se podían realizar para cada tema.

10 Equipo autoral compuesto por Flavio Rapisardi (UNLP), por Roxana Rueda (MDS) y por Verónica Marzano (MDS).

11 La Convención para la Eliminación del todas las Formas de Discriminación contra la Mujer (conocida como CEDAW por sus siglas en inglés: Convention on the Elimination of All Forms of Discrimination against Women), integra nuestro bloque constitucional desde 1994, cuando se la incorporó al texto constitucional en el artículo 75 inciso 22.

12 Convención interamericana para prevenir, sancionar y erradicar la violencia contra la mujer. En nuestro ordenamiento jurídico tiene rango supralegal, es decir, un rango superior a las leyes.

13 Equipo autoral compuesto por Florencia Cremona (UNLP), por Lucas Díaz Ledesma (UNLP) y por Verónica Fulco (MDS).

14 Equipo autoral compuesto por Amalin Ramos (CNM), por Flavia Delmas (UNLP) y por María del Carmen González (MDS).

15 También se abordaron casos resonantes como la desaparición de María Cash y el femicidio de Wanda Taddei. María Cash es una mujer desaparecida en la Argentina desde 2011 en ocasión de un viaje que realizaba por el norte del país. La hipótesis más fuerte para explicar su desaparición remite a una red de trata de mujeres con fines de explotación sexual. Wanda Taddei fue una mujer asesinada por su pareja (exbaterista de la banda de rock Callejeros), un hecho que impactó en la opinión pública por la forma de comisión del femicidio -mediante fuego- y porque inauguró una serie de femicidios cometidos con el mismo modus operandi. Al femicida, Eduardo Vázquez, lo condenaron a prisión perpetua.

16 Esta sentencia del superior tribunal de justicia de la Argentina interpreta de manera amplia el artículo 86 del Código Penal, que establece que el aborto es no punible en caso de violación.

17 En palabras de Montserrat Sargot, citada por Flavia Delmas y por Celina Urtazún (2012): «La Ruta Crítica nos abre una puerta y nos lleva por los caminos que toman las mujeres para salir de su situación de violencia. La Ruta empieza con la decisión y la determinación de las mujeres de apropiarse de sus vidas y las de sus hijos. Siguiendo esta Ruta, conocemos los factores que impulsan a las mujeres a buscar ayuda, las dificultades encontradas para llevar adelante tal decisión, sus percepciones sobre las respuestas institucionales, y las representaciones sociales y los significados sobre la violencia 
intrafamiliar que existen entre el personal de las instituciones que deben ofrecer respuestas a este serio problema de salud pública. Al fin, aprendemos sobre sus frustraciones y sus resignaciones que, en muchos casos, las llevan otra vez a la situación de violencia» (p. 11).

18 Equipo autoral compuesto por Esdenka Sandoval (UNLP) y por Verónica Fulco (MDS).

19 Debo destacar aquí el rol de la tutora en la experiencia de la comisión 2 de la UNQUI. La licenciada en trabajo social, Mariana Gambetta, se ocupó no solo de las cuestiones administrativas del curso sino que estuvo disponible para todos los y las cursantes a efectos de articular con las instituciones pertinentes ante casos de emergencias y de urgencias que se produjeran en los barrios, tanto en relación con las violencias basadas en el género como con todo tipo de situaciones: inundaciones, incendios, etcétera. Su presencia y la forma en la que trabajó con las y los participantes fueron vitales para sostener la propuesta.

20 El femicidio de Chiara Páez - una joven de 14 años embarazada, asesinada por su pareja de 16 años y enterrada en el patio de la familia del femicida-, en Rufino, provincia de Santa Fe, Argentina, provocó la organización del colectivo de mujeres para movilizarse el 3 de junio de 2015 bajo la consigna \#NiUnaMenos, la cual fue histórica por su potencial para visibilizar la problemática. Año a año la movilización se repite en la misma fecha para demandar el derecho a una vida libre de violencias. 